2011-08-01

\title{
Unconsidered activity, craft expertise and reflective practice in teaching
}

Kelly, Peter

http://hdl.handle.net/10026.1/1543

10.1080/14623943.2011.590345

Reflective Practice

Informa UK Limited

All content in PEARL is protected by copyright law. Author manuscripts are made available in accordance with publisher policies. Please cite only the published version using the details provided on the item record or document. In the absence of an open licence (e.g. Creative Commons), permissions for further reuse of content should be sought from the publisher or author. 
This article was downloaded by: [Univ of Plymouth]

On: 13 July 2011, At: 08:47

Publisher: Routledge

Informa Ltd Registered in England and Wales Registered Number: 1072954 Registered

office: Mortimer House, 37-41 Mortimer Street, London W1T 3J H, UK

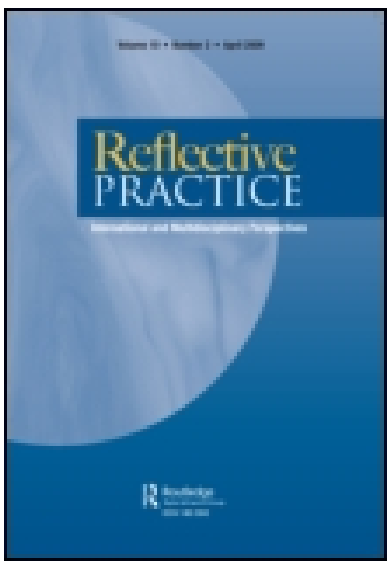

\section{Reflective Practice}

Publication details, including instructions for authors and subscription information:

http:// www.tandfonline.com/loi/ crep20

\section{Unconsidered activity, craft expertise and reflective practice in teaching}

Peter Kelly ${ }^{a}$

a University of Plymouth, Plymouth, UK

Available online: $11 \mathrm{~J} \mathrm{ul} 2011$

To cite this article: Peter Kelly (2011): Unconsidered activity, craft expertise and reflective practice in teaching, Reflective Practice, 12:4, 557-568

To link to this article: http:// dx. doi.org/ 10.1080/ 14623943.2011.590345

\section{PLEASE SCROLL DOWN FOR ARTICLE}

Full terms and conditions of use: http://www.tandfonline.com/page/terms-andconditions

This article may be used for research, teaching and private study purposes. Any substantial or systematic reproduction, re-distribution, re-selling, loan, sub-licensing, systematic supply or distribution in any form to anyone is expressly forbidden.

The publisher does not give any warranty express or implied or make any representation that the contents will be complete or accurate or up to date. The accuracy of any instructions, formulae and drug doses should be independently verified with primary sources. The publisher shall not be liable for any loss, actions, claims, proceedings, demand or costs or damages whatsoever or howsoever caused arising directly or indirectly in connection with or arising out of the use of this material. 


\section{Unconsidered activity, craft expertise and reflective practice in teaching}

Peter Kelly*

University of Plymouth, Plymouth, UK

(Received 3 November 2010; final version received 19 May 2011)

This article provides an account of unconsidered activity drawing principally on the ideas of John Dewey and Richard Sennett. This is done so as to better understand the complexity, worth and limitations of craft expertise in teaching and how it might be improved to better serve all. Four features are proposed: much activity is unconsidered; activity is embodied; activity is purposive; and people adapt their actions in pursuit of goals. An implication of this account is the need for teachers to consider how resultant structured behaviours can bestow advantages on some of their students and not others, and suggestions are made about how this might be done.

Keywords: Dewey; Sennett; social theory; craft; expertise; reflective practice

\section{Introduction}

The aim of this paper is to explore unconsidered participation in teaching, although the perspectives offered could also apply to other complex social activities such as nursing, policing and social work. Much has been written about considered and deliberate action in these areas. Donald Schön's views about the nature of professional practice remain highly influential, whilst more recent perspectives including those of socio-cultural theorist Stephen Billett cast new light on this relation. However the descriptions they provide are unclear, particularly in their consideration of routine behaviours, and all are largely silent about how unequal relations of social power affect practice. In this paper article I briefly discuss these limitations before elaborating their accounts, principally using John Dewey's writings on experience and Richard Sennett's writings on craft expertise. This elaboration shows how teacher behaviours can become patterned in ways which advantage or disadvantage their students, and I highlight important implications of this for practice. Throughout I use the term social activity to mean activity shaped by social considerations.

Neither Schön's account of reflection on and in practice $(1983,1987)$ nor Billett's account of knowing-in-practice (2001) consider in any detail tacit behaviours which are embodied, unarticulated (and to some extent unarticulatable), and of which we may be largely unaware. This is a significant omission if we accept Dewey's (1922) contention that much of our behaviour is such. In this paper article I seek to rectify this omission by looking for a social answer to the questions:

*Email: peter.kelly@plymouth.ac.uk 
- How do such tacit behaviours develop and become patterned (or, in the term more often used by social theorists, structured)?

- How can practitioners best interrogate and modify such patterned behaviours so as to act agentively in the service of all in their communities?

Whilst these have to some extent been addressed at a macro-sociological level (for example, Bourdieu [1993]), I consider here the micro level before linking the micro to the macro.

\section{The Schönian consensus}

Donald Schön $(1983,1987)$ provides a social description of what he calls professional and what I call complex social practice, that is practice directed towards the achievement of complex (alongside routine) social objectives. This account is well known, and I will only provide a brief outline of it here. He considers the knowledge which practitioners draw on to largely comprise knowledge-in-practice encompassing what Sternberg and Horvath (1999) call tacit knowledge: knowledge which is grounded in complex social activity and cannot be fully expressed. Such knowledge can only be created by practitioners in the context of their practice. But whilst knowledge-in-practice may not be fully expressible, for Schön it is the focus of professionals' awareness and consideration. Thus, Schön proposes a process of reflection-in-practice by which practitioners engage in a continuing dialogue with the permanently changing situation of their practice (sometimes called 'thinking on their feet'). In reflection-in-practice and subsequent reflectionon-practice practitioners make sense of their activity, and in so doing draw on both their knowledge-in-practice and their knowledge-of-practice, the latter including their own and others' reflections on and enquiries into practice. But this process is neither linear nor static.

Thus, for Schön, professional practice results from an iterative and dynamic engagement between knowledge-in-practice and knowledge-of-practice through the process of reflection. Knowledge-of-practice could include reflections on previous experiences and their ideas about the nature of their professional work, research including their own practitioner research, guidance and advice, and even the oral craft-lore of the profession. But complex social objectives may be constantly changing, being defined and redefined by the practitioner's ongoing conversation with their practice. Thus, practitioners have an active and productive relationship with their knowledge base. They construct their own knowledge base, in their own particular circumstances, with a view to addressing the particular problems which they have identified, specific to particular groups or individuals and the context of their practice.

For example, a teacher working with a group of students having difficulty understanding how to do a mathematical calculation may draw on her or his knowledge-in-practice (memories of what previous relevant experiences actually felt like and expectations about the effects of particular actions) and knowledgeof-practice (explicit ideas about approaches to teaching such calculations, the common misconceptions students have and ways of overcoming them) in an ongoing reflective personal 'conversation' in which the teacher measures the effects of her or his actions against the student response and adjusts these actions accordingly. This experience may be drawn on subsequently in similar encounters, 
be it either in hunches and remembered but unarticulated actions and effects (that is, knowledge-in-practice) or in newly formulated ideas and opinions resulting from reflective processes (that is, new knowledge-of-practice).

Schön's account is inherently dualistic. By describing the interaction of opposites - knowledge-of and knowledge-in, reflection-on and reflection-in, and, fundamental to these, thinking or reflection and doing or practice - it runs against holistic notions of embodied practice (which I will discuss later). This dualism has consequences. As Eraut (1994, p. 145) suggests, 'when time is extremely short, decisions have to be rapid and the scope for reflection is extremely limited' (1994, p. 145). Certainly, constant considered engagement with professional practice would make considerable demands on the time and energy of practitioners; it feels implausible that practitioners have time to make considered but split-second decisions in the heat of the action.

Schön also 'neglects the situatedness of practitioner experience' (Usher, Bryant, \& Johnston et al., 1997, p. 168). His account is of the individual practitioner conversing with practice, and despite his focus on the social nature of professional practice, Schön's concern is with knowledge as a possession of individual practitioners (Kelly, 2006). As such, it has been criticised by some as having a weak focus on power and politics (Ramage \& Shipp, 2009). Apart from the last, these are concerns which socio-cultural theorists have sought to address.

\section{The socio-cultural challenge}

There is not the space here for a full review of the socio-cultural field. Rather, I will focus only on the work of Stephen Billett (2001), whose views build on those of Schön. Like other socio-cultural theorists, he argues for a view of both coming to know and knowing-in-practice as processes which, rather than lying entirely with the individual, are distributed across all participants (for example, teachers and students within a classroom) and which relate to both the conceptual and the physical resources available.

As an example we can consider again the knowledge for teaching a particular mathematical idea. This emerges from negotiations between teachers and students in relation to:

- the explicit conceptual resources teachers bring, their knowledge-of-practice which might, in this case, include their knowledge of mathematics, their knowledge of pedagogical approaches and their knowledge of common misconceptions students have when learning mathematics;

- the tacit understandings gained from previous teaching and related experience, their knowledge-in-practice which might include adopting an authoritative posture in front of a misbehaving child, talking in a sympathetic manner to motivate and support a child having difficulty or, using variety of clues, getting a feel for when a child needs help or encouragement;

- the resources provided by the classroom, including whether it lends itself to individual or collaborative group work, and whether students have access to a range of mathematical resources including computers and calculators; and

- the conceptual resources and tacit understandings which their students bring, including, for example, their prior learning, their beliefs about mathematics and their disposition to particular learning approaches. 
The iteration between each of these results in knowledgeable activity on the part of participants in the lesson, teachers and students, which Billett (2001) calls knowingin-practice, and which is very much socially shared and distributed across participants and resources. Here knowing-in-practice is a dynamic process resulting from the collective actions of teachers and students together in the context of their own work. It is specific, indeed unique, to particular instances of social practice. Teachers' knowledge-of-practice can contribute to negotiations between students and teachers, but other factors are equally significant - not least being the ways in which teachers' engagement in the working practices of schools affects their thinking about their practice. We can call this the affordances of school practices. Affordances are participants' (often shared) expectations of the kind of things which can be said, thought or done during their engagement in particular social practices. These expectations privilege particular ways of knowing and acting.

Knowing-in-practice is also a constructive process from which those involved remember their experience of participation. Indeed, it is the history of such remembered experiences which forms the basis of participants' subjective knowledge-in-practice, and which can be reflected upon and reified to contribute to their knowledge-of-practice. Thus, from the mathematics lesson the teacher will remember the experience from his or her perspective, and the students will do the same from theirs. But this process is not explored clearly in socio-cultural accounts; although these ideas provide the basis for a view of complex social practice as the outcome of a dynamic relationship between practitioners' and their clients' conceptual resources, the physical resources available, and the affordances and constraints of their workplace, the relation of deliberation and awareness to embodied activity in sociocultural accounts would benefit further elaboration and exemplification, particularly in relation to descriptions of how routine behaviours and unconsidered activity in complex social practice becomes patterned. I provide this elaboration below.

Indeed, as Sawyer (2009) suggests:

Socio-culturalists do not have an adequate theory of social structure and how it constrains and enables individuals. Because most socio-culturalists are psychologists or anthropologists, it's not surprising that they neglect macro social concerns in favor of a focus on individual action and small group behavior. Socio-culturalists have rarely drawn substantively on sociology, political science, or history-disciplines that argue for the irreducibility of macro level entities or structures. (Sawyer, 2002, p. 303)

Neither, for that matter, does Dewey or Sennett, to each of whom I now turn, but I will address this later.

\section{The contribution of Dewey and Sennett}

Socio-cultural perspectives, many of which are rooted in the ideas of Dewey amongst others, concentrate on explaining considered and deliberate social engagement and interaction. But what of far more common forms of social activity that are unconsidered and routine. This ubiquitous phenomenon is, in my view, worthy of attention. Revisiting Dewey's (1896, 1897, 1922, 1925, 1927; Dewey \& Tufts, 1936) ideas on experience, and referencing these to Sennett's (2009) view of craft expertise (he actually uses the gendered term craftsman, but with qualification), I propose four features to help better understand such activity which I will consider in turn: 
- much activity is unconsidered;

- activity is embodied;

- activity is purposive; and

- and people adapt their actions in pursuit of goals.

\section{Much activity is unconsidered}

Although there is much in complex social practice of which the social actor is fully aware and can therefore reflect on, not all aspects are so. Whilst some actions within any given activity may be considered and deliberate, others involve only a partial awareness and most occupy very little attention.

Dewey (1922) uses the term habit to refer to complex, unconsidered behaviours comprising many smaller acts. Walking is a habit which involves many small and coordinated muscular movements. Brought together, the culmination of much adjustment and practice, these acts become skilled behaviours which normally require little explicit consideration. People have many such habits - acquired predispositions - which can include, for example, a tendency to react to a particular social situation in a particular way or a disposition to tackle a particular problem using a particular approach. But Dewey asserts habits are neither fixed and repetitive nor automatic. They evolve and change in constant adaptation to their environment (Dewey, 1922), and can be influenced and adjusted through deliberate (and sometimes moral) choice and action (Dewey, 1925; Dewey \& Tufts, 1936). Defining skill as 'trained practice' $(2009$, p. 37), Sennett (2009, p. 37) sees these processes as central in the development of craft expertise.

Take, say, a student teacher who may bring a number of strategies for maintaining order the first time they manage a lesson. Some will work and some may need adjusting or replacing, and early experiences may be frustrating, even haphazard. But as the student becomes more expert, maintaining order requires less awareness and is more habitual - allowing greater consideration and reflection on children's wider learning (Bromfield, 2006). If a persistently disruptive child is encountered, specific strategies may again become the focus of the student teacher's attention. Sometimes teacherly behaviours may be displayed habitually in inappropriate circumstances - such as when encountering boisterous youngsters on holiday. And the self-consciousness engendered by being observed by a tutor may actually impede the fluency of teaching. In all of this the distinction between aware and unaware is fluid as the things attended to come in and out of focus, and with this sometimes the distinction between an internal commentary on and deliberate command of embodied actions may not be clear.

Although much activity is unconsidered, this is not to say it is purposeless; its purpose is simply unexpressed, set in the activity, and therefore taken for granted. We might habitually follow routines which were purposeful when learnt. But without awareness, these cannot be re-evaluated as circumstances change; so, for the student teacher above, some management techniques may be effective in maintaining order but detrimental to children's learning.

Much of the discussion above is unremarkable but, as I have begun to indicate, has implications when applied to complex social activities like teaching, which I will return to later. This account differs little from early behaviourist explanations of behaviour; the differences become clearer as it is elaborated using Dewey's account of experience. 


\section{Activity is embodied}

Activity is embodied: it involves the situated actions of our whole bodies; it is what we do and feel and not just what we think. We remember much of our experiences of participation in embodied form. This means the experiences of participation are remembered in our muscles, senses and actions, again without necessarily recourse to thinking. As Stafford (2009, p. 16) says, 'We are more than the memories we can effortfully bring to mind'.

Dewey (1922) identifies two aspects to experience: that associated with reflective thought and knowing which has been the focus of Schönian and socio-cultural analysis; and that which is embodied, direct and immediate, here and now. The first allows us to use language to objectify and assign meaning to situations and thus act deliberately (Dewey, 1925). The latter comprises the aforementioned habits, minimally regulated and reflected upon, which privilege particular implicit ways of acting; indeed, Dewey asserts that habits taken together constitute the self, distributed across features of the environment and so situated in it.

Consider swimming or riding a bicycle as physical examples. These are learnt by the whole body in the whole situation, and each part of the body learns how to act effectively and comfortably. Constant feedback in terms of successfully keeping afloat, remaining balanced and/or moving forward allows adjustment in actions and thus improved performance, but these adjustments may well be subconscious, made without awareness. Much of the activity is inexpressible, and whilst awareness and command thinking are significant in learning, they often play little part in expert practice - habitual performance is what is required. Often the body begins to act before one has mindfully decided to; the illusion is that the mind has made a choice, but in fact the response is embodied.

Dewey (1896) rejects mental and physical dualism, resolving this in his concept of experience (Dewey, 1922). The ways people act in social circumstances depend on their often embodied and unarticulated histories of experience of participation. These experiences, comprising a physical sense of their own and other participants' adopted positions, are evoked when similar social circumstances are met and can render particular behaviours more likely, particularly if these are not reflected on. Thus histories of participation in social activity can lead to dispositions (Dewey, 1925), that is regularities in the ways people apprehend and position themselves towards the world, which are in part tacit, implicit, embodied and unarticulated. So, social activity can be consistent, coherent and patterned without the social actors' awareness of or ability to express the meanings or purposes behind their activity and so evaluate or analyse these. Social theorists like Bourdieu (1993) refer to such patterned behaviours as structures. So, a teacher may find boys in the classes they teach more reluctant to answer open questions than girls, and over time develop a tendency to pose only closed questions to boys. This, in turn, may position these boys in an uncontested relation to knowledge and can, again over time, dispose them to see things in straightforward terms. And all of this could happen without any of the actors' explicit awareness.

In social interactions participants contribute a complex of individual and shared histories of embodied engagement. But they also bring ideas, stories and ways of thinking about the context. These two aspects of experience (Dewey, 1922) are inseparable; they happen together. Similarly in craft expertise Sennett (2009) posits an intimate connection between doing and thinking, between the 'how' and 'why' 
of activity; a co-constitution which evolves through the circularity of repetition and practice into a habituated rhythm between problem-solving and problem-finding. As one develops, Sennett asserts, one becomes more problem attuned, and less mechanical.

Such reifications and narratives can help script lived experiences. It may be that some individuals or groups habitually follow scripts, both of talk and activity (Tomkins, 1987), whilst others are choreographed more loosely. Gergen (1999) reports how the stories people tell of themselves as 'always unlucky' or 'ready for the challenge' influence their experience of chronic illness; Sfard and Prusak (2005) discuss the power of narrative identity in constructing the self, and many studies have explored how teachers' narrative constructions help them make sense of or story their working lives (Watson, 2006) and Gergen (1999) describes how people follow narrative constructions in seeking coherence and causality in their lives.

\section{Activity is purposive}

For Dewey (1922), behaviour cannot be explained as responses to simple external stimuli. Instead people participate in their environments, interacting with artefacts and others for a variety of purposes - be it instinctively and impulsively to satisfy biological needs such as hunger, selectively following interests and preferences such as when expressing tastes, or seeking approval, status or influence in meaningful interactions such as through adherence to customs of etiquette at a dinner party, and so on.

Purposes (be they communal such as meeting aims, objectives, targets, and so on, or more individual such as satisfying needs, wants, desires, and so on) influence the way systems, organisations and people do things. The more particular ends are valued or privileged by individuals or communities and thus invested with higher status, or the more particular outcomes are desired by individuals, the greater their influence. It is clear that explicit and stated expectations can drive social behaviours - but so can tacit and unstated ones including those we met earlier in habitual and embodied behaviour, as can shared expectations of what can and cannot be said and done developed through enculturation, where shared histories of practice dispose individuals to adopt group norms. Here, pressure to conform may be largely embodied in feelings of comfort or discomfort, accepting that there is a natural state of things which is not subject to challenge.

Dewey (1922) recognises people's motivation for acting can be internal (such as anticipating satisfaction based on past experience) or external (such as social pressure to conform), but by having social origins is more likely a combination of both (such as social pressure to conform whilst imagining discomfort if one fails to do so); and that both the purpose of activity and the activity itself are in constant dynamic iteration, constructing and reconstructing each other. Sennett's (2009) views of craft expertise illustrate this complexity. Craft experts, he suggests, are dedicated to good work for its own sake and fully engaged in that work. Their focus is entirely on the quality of their work which they aspire to improve, to 'get better and not just get by' (Sennett, 2009, p. 24), but this also leads to personal satisfaction, self-respect and the respect of colleagues, clients and the wider community. However, this brings a tension between the desire for satisfaction and respect which provokes perfectionism, and the goals of effective and efficient working. 
Thus, acts are functional (that is, defined by their purpose and the work they do) and embedded (in context, in systems of meaning, in relation to previous experience, and so on) (Dewey, 1922). Dewey (Dewey \& Tufts, 1936) acknowledges acts may have many purposes or ends, and these might be incompatible, in conflict and subject to ongoing negotiation. This is particularly the case with public services such as schooling which are tasked to achieve many outcomes. These can be complementary, sitting within the same set of assumptions and achievable through similar practices, or they can be achievable only through contradictory practices. Separate organisations and individual practitioners themselves may bring their own view on their purpose which may similarly be complementary or contradictory.

There are many possibilities for people to adopt contradictory positions in complex social practice. Teachers may adopt one teaching approach for a 'core subject' in which high stakes are attached to student exam performance, but a very different approach to teaching a 'non-examination' subject without recognising any contradiction. They may treat different groups of students differently for no apparent reason. And, of course, as has already been mentioned, they may say that they do one thing whilst actually doing something very different.

Kelly (2006) describes how instrumental working practices in schools position teachers as manual implementers of policy and so can assign to them identities as technicians. Sometimes, the purposes assigned to individuals though social pressures to conform may not actually suit their best interests. They may meet the needs of groups other than themselves. An example of this might be someone's willingness to accept or even defend discriminatory practices against themselves in a society where such practices are socially acceptable or expected, because they anticipate the discomfort brought by their resistance, or even uncritically accept their marginalisation as the natural order of things. But whilst they are discriminated against, another group (in whose interests things are organised) benefits from privileged treatment.

A significant concern here is that when particular purposes are privileged, others are sidelined. For example, in schooling it has long been understood that successful pupils understand the assessment systems within the classroom, and put their energies into meeting these rather than spending too much time on things which are not assessed and therefore not rewarded (Doyle, 1983, 1986). This has led to educational researchers like Doyle to conclude that where assessment leads, the curriculum follows - in many cases narrowing the curriculum to only that which is assessed. So if teachers adopt approaches to assessment which only test a narrow range of approaches to, say, calculation in mathematics, this might lead other areas of mathematics to be ignored, or students to see little value in them.

\section{People adapt their actions in pursuit of goals}

Dewey (1896) asserts that explanations of complex human experience cannot be assembled from simple and separate parts. Rather he sees humans' behaviour as continuously adaptive towards better functioning in their environment, function being defined by their purpose and the work do they do. Thus, he suggests it is in the nature of organisms that they interact continuously with their environments in a manner that is cumulative and mutually modifying (Dewey, 1897, 1922, 1925).

People adapt their behaviours either individually or socially to achieve shared goals, and as already mentioned, the more significant the objective, the greater its 
influence. This adaptation is often unplanned and may be unpredictable; embodied activity which best leads to the achievement of particular significant objectives survives, whilst that which doesn't dies out, and these actions are remembered and brought to bear on subsequent occasions. This increase in participants' competence can happen without participants' attention to it. So, from an earlier example, in becoming more expert as a teacher, one might develop the capability to control a class without being able to articulate the strategies one is using to do this.

Although such goals need not be explicit nor actions deliberate for this to happen, often with explicit goals this adaptive process can be accelerated by deliberate activity. An example of this is sports coaching. The coach focuses on the particular physical skills which make up expert performance. They provide activities which focus on aspects of expert performance, and give immediate feedback to, say, athletes during or immediately after their performance. The aim throughout is improving competitive sporting outcomes. Through this process athletes, swimmers and the like improve much more quickly than they would do through adaptive trial and error.

So, stated simply, people's participation in complex social practice is largely unconsidered, embodied, embedded and functional.

\section{Implications for practice}

A Deweyan perspective challenges the dualism of Schön $(1983,1987)$, for whom reflection links knowledge to practice and that of socio-culturalists like Billett (2001), who replaces Schön's noun knowledge with the verb knowing. Rather, Dewey presents activity as often routine and unconsidered, in keeping with socially shared or habitually adopted norms and expectations, and built on previous embodied and socially embedded experiences. Such behaviour is patterned or structured. But people can also deliberately pursue explicit goals. In this we should note that being unconsidered is not the same as being unaware of activity. Indeed, the distinction between being aware and unaware is fluid, as things attended to come in and out of focus. This relationship is elaborated by Sennett (2009). Craft experts are dedicated to good work for its own sake, fully engaged in that work and always aspiring to improve. They enjoy much personal satisfaction and the respect of others. Their skills are embodied, socially embedded and distributed. Although trained through constant repetition, their skills evolve flexibly and are not directed towards a fixed end. And in craft expertise there is an intimate connection between doing and thinking, the physical and mental, and the 'how' and 'why' of activity, which evolves through the circularity of repetition and practice into habit, and which involves a rhythm between problem-solving and problem-finding.

This perspective problematises reflection in social activity. As people become more expert, attending to some of the things normally done habitually can impair performance. For example, experienced teachers often report making uncharacteristic errors when observed by a senior manager or inspector. Here expert performance is most efficient when it is largely unconsidered and embodied. Visceral knowledge of how to act routinely is what Ball (2003) calls practical sense and Bourdieu describes as 'strategies devoid of strategic design' (1990, p. 108). It may well encompass the best ways of achieving particular goals in particular social circumstances. Indeed, Sennett suggests repetition and practice help convert ideas and embodiments into the instinctive, tacit knowledge accompanied by awareness and 
rationalisation in craft expertise. For Sennett we mustn't simply privilege rational knowledge.

Whilst some aspects of expertise are routine, not all are so, and Sennett asserts craft experts often work in a space between problem-solving and problem-finding with new problems emerging from the solution of earlier ones. Teachers facing non-routine problems may need to act in a considered and reflective manner. But the focus of such considerations may simply be to reconfigure problems so that they can be addressed using routine principles, stories or actions in their solution and so close the process of problem finding; reflection on critical incidents of non-routine problem-solving could be important in identifying and interrogating this. In this regard the keeping of professional journals to record such processes is important because these can later be reflexively interrogated to uncover and challenge preconceptions and assumptions.

But notions of craft expertise as largely practical are limiting. This is not the perspective presented here, which calls on teachers to hold their professional actions to account by deliberately seeking problems through reflection. They may look for patterns or contradictions in practice, ascertaining whom these privilege and whom they do not, and deliberately changing practice accordingly. For example, a group of teachers working in a school serving a socio-economically disadvantaged area tend towards using problem-solving approaches linked strongly to real-life contexts, because these engage most students in their work and promote learning. Over time such approaches become central to school culture, and their effectiveness is accepted unquestioningly. Through enculturation the work of new teachers also becomes patterned thus. But despite their success, such approaches fail to help students understand the principles of abstraction, and so they are disadvantaged by an excess of such teaching when much academic attainment depends on the ability to deal with the abstract. In such cases teachers are called on to use the sociological imagination (Wright Mills, 1959) to 'make visible what is rendered invisible through the society's institutional procedures, and through the daily practices of its members' (Bernstein, 1975, p. 157), and to interrogate patterned behaviours or structures (Bourdieu, 1993) and their associated goals in practice. Bourdieu (1992, 1993) sees reflexivity as central to the capacity of individuals to recognise forces of socialiszation and act agentively.

How might they do this? Sennett suggests craft experts seek problems, and are curious about, investigate and learn from ambiguity. In the example above, teachers might look for students advantaged in important areas of assessment, and then seek ways to support those less advantaged in ways which best suit their needs. But, in seeking problems like this, explorations should necessarily draw on a variety of people, perspectives and data to provide a diversity of viewpoints, considering these through different explanatory frames and social theories. Critical practitioner research approaches can give confidence to evaluations of practice - in this example, perhaps the evaluation of approaches for teaching about abstraction with socioeconomically disadvantaged students. Thus, a consideration of ways to promote practitioner research approaches is important, and certainly institutional cultures are significant. In this Sennett suggests craft expertise in a community is often best when it is collaborative, when communication is completely open, and when there are shared goals and practices.

Nevertheless, a Deweyan perspective does suggest the importance of attending to both the rational dimensions of experience and the affective. So, whilst some 
teachers might rationalise a dilemma into contradictory positions, others might sense dissatisfaction and frustration; and whilst some might make a rational choice, others might intuit a course of appropriate action. In each case one should be sensitive to all aspects of experience whilst also seeking to make visible the tacit or affective so these can be interrogated. But it is important to remember that when embodiments are put in words they are changed; words can never fully capture the tacit and implicit, and the more one reflects on embodied practice the further one moves away from it. In this regard it should be noted that immediate descriptions of lived experience based on actual events have a different status to reflective accounts, the former being much closer to actual practice. Nevertheless, all constructive, meaning-making activity, whether descriptive or more reflective, is structured, and so again it is important that a reflexive stance is adopted. No doubt the construction of representations of practice is limited if confined solely to traditional scholarly approaches; other forms of representation (such as stories, poetry, dance, drama and film) might also illuminate the visceral in social practice (Leitch, 2006).

So, the Deweyan stance outlined in this article suggests teachers, through their patterned behaviours, can unwittingly contribute to such macro-sociological structuring as the reproduction of socio-economic inequalities through schooling (Bernstein, 1975). For some, the suggestions I provide for what teachers might do about this will seem unremarkable: focusing on critical incident analysis of non-routine practice; using critical practitioner research, analysed from multiple perspectives, to deliberately problematise and redress the way school work advantages some but not all students; promoting reflexivity in journal keeping and other ways of representing practice beyond traditional scholarly approaches; and developing collaborative critical working cultures. But these suggestions are made within a complex and nuanced frame for understanding teaching, a frame which should alert us to the difficulty of tackling the issues raised. Each suggestion is made to help illuminate habitual, unconsidered, patterned activity; not something to be taken lightly. Their significance can only be fully appreciated when both the importance and challenge of interrogating practice is recognised as a central to the craft expertise of teaching.

\section{Notes on contributor}

Peter Kelly is associate professor in Education and leads the International Masters Programme in the Faculty of Education at the University of Plymouth.

\section{References}

Ball, S.J. (2003). Class strategies and the education market: The middle class and social advantage. London: Routledge Falmer.

Bernstein, B. (1975). Class, codes and control: Towards a theory of educational transmission, (Vol. 3). London: Routledge and Kegan paul.

Billett, S. (2001). Knowing in practice: Re-conceptualising vocational expertise. Learning and Instruction, 11(6), 431-452.

Bourdieu, P. (1990). The logic of practice. Cambridge: Polity Press.

Bourdieu, P. (1992). Invitation to a reflexive sociology. Chicago, IL: University of Chicago Press.

Bourdieu, P. (1993). The field of cultural production. London: Sage.

Bromfield, C. (2006). PGCE secondary trainee teachers and effective behaviour management: An evaluation and commentary. Support for Learning, 21(4), 188-193.

Dewey, J. (1896). Critique of the reflex arc concept in psychology. In J. Boydston (Ed.), (1969-72), The early works of John Dewey, Vol. 5. Carbondale, IL: Southern Illinois University Press.

Dewey, J. (1897). My pedagogic creed. In J. Boydston (Ed.), (1969-72), The early works of John Dewey, Vol. 5. Carbondale, IL: Southern Illinois University Press. 
Dewey, J. (1922). Human conduct and nature. In J. Boydston (Ed.), (1976-88), The middle works of John Dewey, Vol. 14. Carbondale, IL: Southern Illinois University Press.

Dewey, J. (1925). Experience and nature. In J. Boydston (Ed.), (1981-91), The later works of John Dewey, Vol. 1. Carbondale, IL: Southern Illinois University Press.

Dewey, J. (1927). The search for the great community. In J. Boydston (Ed.), (1991-91) The later works of John Dewey, Vol. 2. Carbondale, IL: Southern Illinois University Press.

Dewey, J., \& Tufts, J. (1936). Ethics. New York: H. Holt.

Doyle, W. (1983). Academic work. Review of Educational Research, 53, 159-200.

Doyle, W. (1986). Classroom organisation and management. In M. Wittrock (Ed.), Handbook of research on teaching. New York: Macmillan.

Eraut, M. (1994). Developing professional knowledge and competence. London: Falmer.

Gergen, K. (1999). An invitation to social construction. London: Sage.

Kelly, P. (2006). What is teacher learning? A socio-cultural perspective. Oxford Review of Education, 32(4), 505-519.

Leitch, R. (2006). Limitations of language: Developing arts-based creative narrative in stories of teachers' identities. Teachers and Teaching: Theory and Practice, 12(5), 549-569.

Ramage, M., \& Shipp, K. (2009). Systems thinkers. London: Springer-Verlag.

Sawyer, R. Keith. (2002). Unresolved tensions in socio-cultural theory: Analogies with contemporary sociological debates. Culture \& Psychology, 8(3), 283-305.

Schön, D. (1983). The reflective practitioner: How professionals think in action. New York: Basic.

Schön, D. (1987). Educating the reflective practitioner. San Francisco, CA: Jossey-Bass.

Sennett, R. (2009). The craftsman. London: Penguin.

Sfard, A., \& Prusak, A. (2005). Telling identities: In search of an analytic tool for investigating learning as a culturally shaped activity. Educational Researcher, 34(4), 14-22.

Stafford, T. 2009. Letters: Craig Brown's memory. Prospect, September.

Sternberg, R., \& Horvath, J. (1999). Tacit knowledge in professional practice. London: Lawrence Erlbaum.

Tomkins, S. (1987). Script Theory. In J. Arnoff, A.I. Rabin \& R.A. Zucker (Eds.), The emergence of personality. New York: Springer Publishing Company.

Usher, R., Bryant, I., \& Johnston, R. (1997). Adult education and the postmodern challenge. London: Routledge.

Watson, C. (2006). Narratives of practice and the construction of identity in teaching. Teachers and Teaching: theory and practice, 12(5), 509-526.

Wright Mills, C. (1959). The Sociological Imagination. London: Oxford University Press. 